\title{
Erratum: T cell recognition of lipids: quo vadis?
}

Gennaro De Libero, H Robson MacDonald \& Paolo Dellabona

Nat. Immunol. 8, 223-227 (2007); published online 15 February 2007

In the version of this article initially published, the 'Competing Interests Statement' section was missing. The section should read as follows: COMPETING INTERESTS STATEMENT

The authors declare no competing financial interests. 